\title{
GUERRA HÍBRIDA: ANÁLISE DE UMA PERSPECTIVA1
}

HYBRID WARS: ANALYSIS OF A PERSPECTIVE

DOI: 10.5380/cg.v10i1. 75867

José Paulo Toledo²

Talissa Gabriela Ritrovati3

\begin{abstract}
Resumo
Em seu texto publicado em 2015, Andrew Korybko faz uma análise da nova metodologia empregada pelos EUA para interferir na política interna de nações em áreas estratégicas para sua geopolítica. Neste estudo pautado pelo conceito de guerra híbrida, o autor mostra como esse processo de interferência externa conta massivamente com o uso de análise de dados e abordagem indireta para criar o que se chama de armamentização do caos, ou a utilização do caos social como forma de cooptação de uma parcela da sociedadealvo que trabalhará ativamente contra seus interesses nacionais sem nem perceber: para exemplificar essa dinâmica, faremos uma breve análise do contexto brasileiro com base no conceito proposto pelo autor. Neste texto, sugerimos que o potencial explicativo do conceito como proposto por Korybko para analisar contextos sociopolíticos atuais é grande e, quando combinado aos mais tradicionais temas e teorias de diferentes áreas das ciências sociais, pode criar uma renovação teórica interessante para os desafios enfrentados pelas mesmas neste momento histórico. $\mathrm{O}$ artigo está divido em cinco tópicos diferentes, abordando em primeiro lugar o contexto que permite a existência da guerra híbrida e o que a justifica; no segundo momento, analisamos o processo de desenvolvimento dessa técnica; no terceiro, analisamos como ela ocorre pacificamente, enquanto no quarto, analisamos qual o papel da violência; no quinto, fechamos o raciocínio concluindo que o conceito pode enriquecer debates que abordem a corrosão das democracias.
\end{abstract}

Palavras-Chave: Guerra híbrida; Geopolítica; Revoluções coloridas; Guerra de quarta geração; América Latina.

\begin{abstract}
In his text published in 2015, Andrew Korybko analyzes the new methodology employed by the USA to intervene in the internal political affairs of nations in strategic areasfor its geopolitical power. In this study based on the concept of hybrid warfare, the author shows how this process of external interference relies massively on the use of data analysis and indirect approaches to create what is called the weaponization of chaos, or the utilization of social chaos as a way to co-opt a portion of the target society that will actively work against its national interests without even noticing it: to exemplify this dynamic, we will do a brief analysis of

\footnotetext{
${ }^{1}$ Artigo originado de uma pesquisa financiada com recursos da Coordenação de Aperfeiçoamento de Pessoal de Nível Superior (CAPES). Licenciado sob a Licença Creative Commons Attribution (CC BY 4.0), sendo permitido o compartilhamento com reconhecimento da autoria e publicação inicial nesta revista. Os autores agradecem aos pareceristas anônimos por suas contribuições ao texto final.

${ }_{2}^{2}$ Mestrando em Ciência Política pela Universidade Federal de São Carlos e graduado em Ciências Sociais, com ênfase em Ciência Política, pela mesma instituição. E-mail: zepatoledo@gmail.com. ORCID: https://orcid.org/0000-0002-0583-5352.

3 Graduanda em Ciências Sociais pela Universidade Federal de São Carlos, integrante do Laboratório de Estudos Sobre Militares (FGV). E-mail: talissaritrovati17@gmail.com. ORCID: https://orcid.org/o000-00029286-5647.
} 
the Brazilian context based on the concept created by the author. In this text we suggest that the explanatory potential of the concept as proposed by Korybko to analyze current sociopolitical contexts is great, and, when combined with the more traditional themes and theories from different areas of the social studies, can create an interesting theoretical renewalfor the challenges faced by them at this historical moment. The paper is divided in five different topics, addressing first the context that allows hybrid warfare to exist and what justifies it; in the second movement, we analyze the development of this technique; in the third, we explain how it occurs peacefully, while in the fourth, we analyze how analyze what role violence plays, in the fifth we lose the reasoning by concluding that the concept can enrich debate that address the corrosion of democracies

Keywords: Hybrid wars; Geopolitics; Colored revolutions; Fourth generation warfare; Latin America.

\section{INTRODUÇÃO}

Andrew Korybko4 afirma em seu livro de 2015 que "a guerra híbrida é o caos administrado" (2018, p.33). Com esse conceito, o autor busca sintetizar em poucas palavras uma dinâmica desenvolvida ao longo de muitos anos pelos Estados Unidos da América para atuar especificamente em regiões classificadas como estratégicas na busca da manutenção de sua supremacia global. Sendo especialista em relações geopolíticas euroasiáticas, Korybko faz sua análise focando nos processos de desestabilização, ou nas guerras híbridas, que ocorrem em tal região.

Neste artigo, faremos uma breve relação: uma introdução ao contexto histórico e técnico que permite entender em profundidade o debate, um sintético resumo da teoria organizada pelo autor mesclada à leitura que tal teoria possibilita ser feita da realidade geopolítica e social brasileira, indo da macroescala geopolítica até a micropolítica do papel de indivíduos nos movimentos. Ao final, uma conclusão com uma intenção explícita: defender primeiramente uma interpretação da natureza teórica da guerra híbrida não como um texto guia político, mas como a descrição de uma técnica. Este artigo tenta levar esse conceito para novos ambientes dentro da academia, tendo em vista que já existe um debate sólido sendo feito ao redor dele por especialistas de ciências militares, como Leal (2016), e antropologia dos militares e do Estado em Leirner (2020), mas apenas recentemente o conceito passa a estar presente em obras dentro de áreas como a ciência política, as relações internacionais e a sociologia, altamente correlacionadas com o arcabouço teórico proposto. Dessa forma, tentamos contribuir para a disseminação do mesmo tendo em vista seu potencial explicativo quando combinado aos mais tradicionais temas e teorias das ciências sociais.

A tese que Korybko (2018) defende tem três eixos centrais: a) a luta pela manutenção da hegemonia estadunidense, ou em outros termos, a renovação do imperialismo; b) as Revoluções Coloridas; c) as Guerras Irregulares. O primeiro eixo diz respeito à motivação estadunidense para agir, enquanto o segundo e terceiro são relativos ao modo de agir.

A supremacia geopolítica estadunidense foi plenamente conquistada em 1991, com a queda da União Soviética, o fim do mundo polarizado entre a potência ocidental e oriental e uma vitória do

4 Jornalista da Sputnik News, analista político e conselheiro do Institute for Strategic Studies and Predictions. 
modelo econômico capitalista sobre o socialista proposto pela URSS, criando então uma necessária e ampla reorganização global de relações, indo das econômicas até as militares, por exemplo (MOSKOS; WILLIAMS; SEGAL, 2000). O impacto dessa ideia no imaginário coletivo ocidental pode ser claramente visto com a já saturadamente citada tese de Francis Fukuyama, O Fim da História e o Último Homem (1992), com a aceitação de que a democracia liberal ocidental se firma como o melhor caminho para o desenvolvimento da humanidade, tese reforçada pelo processo de globalização e crescimento econômico mundial no período pós-soviético.

Esse dado deve ser interpretado de forma realista: o crescimento econômico no período foi tocado pela financeirização econômica maturada durante os anos 1980 combinada à concentração de renda nos centros do sistema capitalista. O desenvolvimento tecnológico logístico e produtivo, a inclusão dos antigos países soviéticos no mercado internacional e a pressão sobre as economias subdesenvolvidas e em desenvolvimento foram centrais para financiar o crescimento no período, havendo então uma concentração de toda a riqueza produzida no período. "Pode-se afirmar, assim, que os países pobres financiaram, em grande medida, o processo de recuperação dos países ricos e a retomada da hegemonia global norte-americana” (GASPAR, 2015, p.284). Como mostra o Gráfico 1:

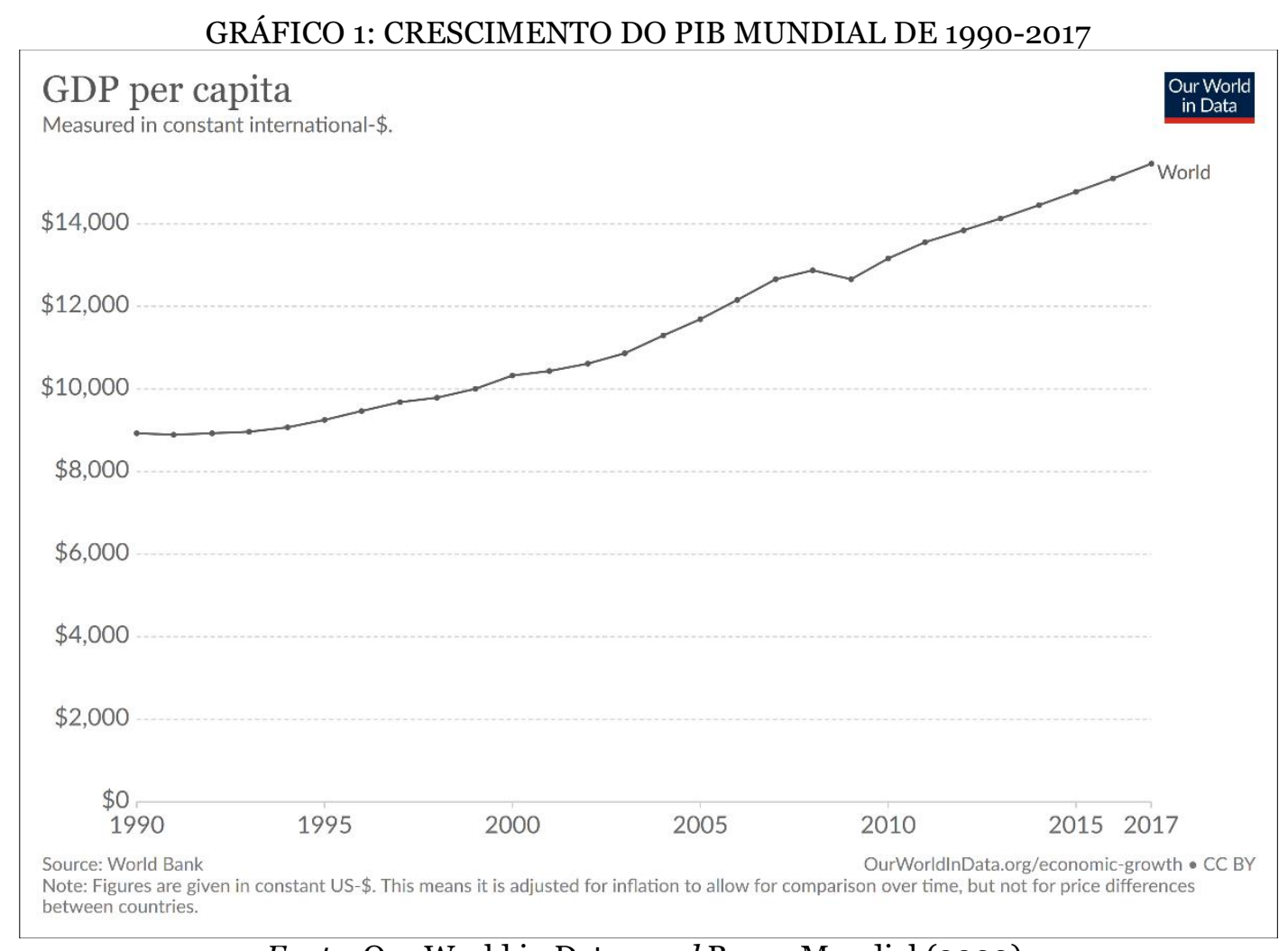

Fonte: Our World in Data apud Banco Mundial (2020).

Esta perspectiva esbarra em dois pontos progressivamente desvelados: primeiramente, a economia planificada chinesa, notoriamente conhecida pela interferência estatal e ligação com a guia política comunista-marxista, passa a crescer como um dos principais atores na economia mundial, acumulando impressionantes excedentes de dólares desde os anos 1990, com um superávit de 
exportações, enquanto os EUA tinham déficits quase proporcionais, transformando-se em uma das maiores economias globais em pouquíssimo tempo; Mendonça (2019, p.41) diz que "É interessante verificar a simetria que se produziu entre este excedente da China e o défice da balança corrente americana, quer em dólares [...] quer em percentagem do PIB [...]”. Depois disso, a crise de 2008, sendo lida como um fato endógeno do sistema capitalista de livre mercado que funciona baseado na intensificação da concentração de renda e capital, mostra que esse "melhor caminho" ainda estava longe da perfeição, causando brutos danos nas economias centrais do sistema econômico global unicamente por uma falha inata ao mesmo.

A partir de 2008, a economia de livre mercado passa a entrar em crises sucessivas com intervalos cada vez mais curtos de aguda acumulação de renda e capital, dado que exprime um fato: para fazer a manutenção do padrão de vida normalizado nos centros do sistema e manter a ordem social dentro de seus territórios, será necessário retirar as riquezas já produzidas das periferias nos anos 2000, período de boom da economia mundial chefiado pelo ciclo das commodities, transferilas aos centros e, ainda, sangrar as riquezas até então intocadas para financiar este projeto.

\section{DESENVOLVIMENTO TÉCNICO}

Os EUA tradicionalmente são intervencionistas para fazer a manutenção de sua supremacia global, interferindo em assuntos internos de países soberanos de modo que seus interesses sejam respeitados: podemos citar inúmeros exemplos dessa dinâmica repetindo-se por todos os continentes: dos esforços feitos pelo Governo Kennedy para a Operação Condor ao treinamento das guerrilhas do Talibã no Oriente Médio e Ásia Central; da Guerra da Coreia durante a Guerra Fria até a Guerra do Golfo na década de 1990 e a Guerra ao Terror nos anos 2000. Com o decorrer do tempo, esse intervencionismo foi progressivamente otimizado, indo das intervenções militares em larga escala custosas financeira e politicamente, como no Vietnã, passando pela abordagem indireta com o treinamento de guerrilhas entre rebeldes nativos, como no Afeganistão, chegando então ao entender de que a cultura pode ser utilizada como uma arma; a relação histórica entre antropologia e organizações militares é muito bem descrita por Leirner (2016), descrevendo como isso se deu desde o século XIX até a atualidade, quando se entendeu que a cultura pode ser utilizada como uma arma e buscou-se instrumentalizar essa funcionalidade. Esse pensamento é materializado no Human Terrain System, programa implementado no Iraque durante os anos 2000, que colocava dentro de diversos esquadrões cientistas sociais, tendo estes a função de descrever as comunidades onde atuavam e sua cultura, para que isso pudesse ser usado tanto no processo decisório do comando quanto como instrumento tático de campo. Este processo de transformação da cultura em arma abre uma nova chave para a forma com que se pensa a guerra em si. 
Estes atores passam a desenvolver a síntese da armamentização da cultura com outra teoria, a dominação de espectro total, definida como "o efeito acumulado de superioridade aérea, terrestre, marítima, e espacial e dos ambientes de informação que permitem a condução de operações conjuntas sem oposição efetiva ou interferência proibitiva" (DEPARTMENT OF DEFENSE, p. 220, 2007, tradução e grifo dos autores)5. As duas apontam para a mesma direção: se a guerra total é definida como "conflito armado no qual os beligerantes empregam todo o seu Poder Nacional, sem restrições quanto aos métodos e engenhos e mesmo quanto às leis convencionais de guerra" (MINISTÉRIO DA DEFESA, p.127, 2007), ela já não basta. Se a cultura e os meios de informação são armas, então a sociedade em sua plenitude é um campo de batalha e, assim, o controle sobre cada indivíduo é ganho de terreno, esfacelando-se aqui qualquer fronteira entre paz e guerra. Tudo é planejado e analisado em função de guerra o tempo inteiro, e a política passa a ser a guerra por outros meios.

Dados os contextos geopolíticos e técnicos, é possível entender um breve resumo da tese de Korybko (2018): as maiores economias que poderiam ameaçar a supremacia estadunidense no mundo se encontram na Ásia, sendo elas Rússia e China. Os Estados Unidos não podem fazer um assalto frontal contra nenhum dos dois países, tendo em vista que são potências nucleares, fazendo da abordagem indireta a única possibilidade de ação. Essa ação, se feita dentro dos países-alvo na atualidade, pode ser interceptada e tornar-se um grande incidente diplomático.

Para driblar tal fim, o melhor método encontrado para atrapalhar o desenvolvimento dessas potências é através da criação de caos regional, interferindo na política interna de vizinhos menos poderosos dessas potências, instalando neles governos de procuração da Casa Branca, podendo ter dois efeitos adversos nelas: a) impedir o crescimento econômico por associação com esses países, que poderiam ser seus aliados estratégicos ou parceiros comerciais; b) fazer com que o caos dentro desses países vizinhos transborde para dentro das fronteiras dos países-alvo, criando, na melhor das hipóteses, um problema a mais, que demandará recursos e esforços para resolver, retirando tais recursos e esforços de um melhor emprego. Dada a função estratégica geopolítica da guerra híbrida, o autor passa às tecnicidades ligadas ao conceito: como instalar um governo fantoche e criar o caos? Ele separa essa dinâmica em dois movimentos: a revolução colorida e a guerra irregular.

A revolução colorida é assim chamada por, primeiramente, ser pacífica e apelar aos valores de renovação política e ascensão da juventude. Baseada em uma bibliografia e prática desenvolvida por meio do estudo e teste de métodos pacíficos de desestabilização de regimes, principalmente os escritos de Gene Sharp6: From Dictatorship to Democracy - A Conceptual Framework for Liberation (2010); The Anti-Coup (2003); Self-Liberation: A Guide to Strategic Planning for Action to End a

\footnotetext{
5 "The cumulative effect of dominance in the air, land, maritime, and space domains and information environment that permits the conduct of joint operations without effective opposition or prohibitive interference"

${ }^{6}$ Smith (2020) oferece um perfil mais detalhado e crítico das obras, do intelectual e de sua trajetória política ligada à Casa Branca.
} 
Dictatorship or Other Oppression (2009). Todas essas publicações são vinculadas à Albert Einstein Institution, fundada por Sharp, cujos compromissos autodeclarados são "defender as liberdades democráticas e as instituições; opor-se à opressão, ditaduras e genocídios; reduzir a confiança na utilização de violência como instrumento político". Belos fundamentos morais são constantemente justificativas imperialistas para interferência na política interna de outras nações, e os vínculos dessa instituição com o aparato bélico estadunidense denuncia seu caráter. Essas "revoluções" têm como eixo central sua estética: movimentos espontâneos, a ocupação de espaços públicos com atividades culturais e diversidade, a criação de novos atores políticos vindos de uma juventude; não à toa, as pautas políticas são bandeiras genéricas, como a já citada "renovação política" ou "combate à corrupção", permitindo que haja uma elasticidade nas pautas para um segundo movimento do processo.

Entretanto, isso pode parecer demais: como articular tão magistralmente um movimento desse porte, tanto explorando a explosão quanto definindo seu direcionamento? Três respostas: data science, controle de informação e criação de lideranças.

\section{REVOLUÇÕES COLORIDAS}

\subsection{DATA SCIENCE}

Ciência de Dados, ou data science, é um campo das ciências da computação baseado na utilização de big data: o conjunto de dados gerados na internet por todos os seus utilizadores; no Brasil, temos aproximadamente 134 milhões de produtores de dados (VALENTE, 2020). O trabalho do cientista de dados é analisar esse oceano de dados em busca de um conjunto de informações específicas que auxiliarão no processo de tomada de decisões do ator com quem ele trabalha; é interessante compreender "dado" como a informação não refinada, perdida em meio de todas as outras. Logo, "informação" é o dado trazido a um contexto específico para auxiliar em seu entendimento ou resolução. (KENETT; REDMAN, 2019). "Quão confiável é esta área para tal atuação?”, pode se perguntar o leitor mais cético. Em uma brevíssima pesquisa, verá que a utilização destes profissionais por empresas hoje é um campo em constante e agressiva expansão, mesmo em um período de acentuada crise econômica mundial (CIO, 2020; DATA SCIENCE ACADEMY, 2020; EXAME 2019).

Isso ocorre porque a capacidade do cientista de dados de se aproveitar de todos os dados disponíveis na internet para discernir comportamentos de determinados públicos em relação a determinados produtos cria um trunfo, ligando diretamente anseios dos consumidores com os coordenadores do sistema produtivo, criando uma espécie de toyotismo otimizado onde não só pode se vender sob demanda e não só pode-se criar uma demanda específica, como também ofertá-la a 
um público especificamente vulnerável a ela, chegando ao ponto de criar uma desvalorização da publicidade convencional (VICARIO; COLEMAN, 2020, p.7).

Agora, esse potencial existe em função da possibilidade de definir diferentes estratos da sociedade e seus desejos, suas inclinações de valores morais e propensão à aceitação de determinados estímulos, como sendo mais afetados por felicidade, medo, raiva, inseguranças específicas e afins. Como exemplo, podemos olhar para a Cambridge Analytica, empresa de consultoria política utilizada pela campanha de Donald Trump em 2016. O chefe do departamento de data science da empresa, posterior delator, descreve a atuação da empresa dizendo que "a companhia criou o perfil psicológico de 230 milhões de americanos. Agora eles querem trabalhar com o Pentágono? É como Nixon com esteroides” (CALWALLADR, 2020. Tradução dos autores)7.

Dados os paradigmas já apresentados resultantes da ruptura entre as fronteiras de paz e guerra, não é coincidência que o Pentágono contrate milhares de cientistas de dados anualmente e ainda tenha um déficit de profissionais da área (LOEB; MOORE, 2020). No final das contas, isso criou uma enorme oportunidade para propagar ideologias de forma cirúrgica, como, por exemplo, sabendo que ligar manifestações com uma estética semelhante às Diretas Já, apelando às cores da bandeira nacional a um público de uma classe média afogado em um antipetismo naturalizado ${ }^{8}$. Associando a isso valores reacionários, muitas pessoas fariam parte do movimento mais pela inércia criada pela estética nacionalista-renovadora do que por uma real identificação política, sendo convencidas a adotar esse referencial reacionário no decorrer do movimento. Como já dito, o próprio movimento inicial não tem caráter definido. O que faz desse movimento, então, menos uma aposta e mais um plano? Como saber que, após o início deste processo, ele não vai simplesmente sair de controle por meio das inúmeras variáveis completamente alheias?

\title{
3.2. CRIAÇÃO DE LIDERANÇAS E CONTROLE DE INFORMAÇÃO
}

Apesar dessa estética depender de um aparente espontaneísmo, ele é necessariamente uma ilusão. Citando o autor,

\begin{abstract}
Não importa se esses acontecimentos ocorreram de verdade ou não. O que importa é como eles são percebidos, retratados e narrados para o público em geral. Alegações, e não provas, dos itens acima são o que mais importa para criar o catalisador para um acontecimento. Deve-se ter sempre em mente que o movimento pode provocar qualquer um desses acontecimentos (ou a falsa percepção de que eles ocorreram) (KORYBKO, 2018, p.126).
\end{abstract}

\footnotetext{
7 "The company has created psychological profiles of 230 million Americans. And now they want to work with the Pentagon? It's like Nixon on steroids.”

8 "As pesquisas indicam que há uma frustração dos eleitores com candidatos tradicionais e o desejo por um outsider", diz um trecho do relatório. "A classe média brasileira é creditada como sendo a força popular por trás dos protestos de 2013, e o Nordeste tem um alinhamento forte com Lula e o Partido dos Trabalhadores. Se os métodos da CA [Cambridge Analytica] forem eficazes, a situação política do Brasil pode ser chacoalhada[...]." (CAMBRIDGE ANALYTICA apud GAGLIONI, 2020).
} 
Anteriormente ao movimento, há uma fase de preparação para que, ao acender o pavio, as lideranças ligadas à agenda estadunidense estejam preparadas para assumir o papel de representantes legítimos da renovação; treinamento em think tanks, capacitação para financiamento autônomo tutelado por empresas multinacionais 9 e treinamentos feitos até mesmo pelo próprio Estado estadunidense, vide juízes da operação Lava Jato e o Projeto PONTES ${ }^{10}$, garantindo que no topo dos movimentos estejam procuradores de interesses estrangeiros. Entretanto, por si só, essa iniciativa daria a possibilidade de que as bases criassem lideranças autônomas a partir de diferentes interpretações da realidade, aspirações ou projetos.

O domínio sobre as bases ocorre por meio do controle de informações. Esse processo vai ser centrado no eixo da manipulação de narrativas por meio das redes sociais e aplicativos de mensagem instantânea, usados para dividir a sociedade em polos opostos, ponto central na aplicação da guerra híbrida, sendo este também o instrumento de sua manutenção: cismogênese (LEIRNER, 2020, p.175-179). Aqui aplica-se todo o conhecimento técnico da ciência de dados para mapear uma sociedade focando em um método quantitativo que, explorando as preferências, os valores, os principais problemas sociais e posições políticas, cria um arcabouço do que é a sociedade-alvo e quais suas maiores vulnerabilidades sociopolíticas; não são poucos os estudos sobre os movimentos pós2013 que descrevem haver uma vulnerabilidade específica na sociedade brasileira desse momento:

Existem evidências de que o pensamento de direita, o antipetismo e a ambiguidade em relação ao apoio à democracia se encontram disseminados entre os manifestantes contra o governo Dilma Rousseff, e que parcelas das camadas médias estão atentas e sensíveis às propostas ideológicas de direita (TELLES, 2016, p.99).

Além de Telles (2016) e Cepêda (2018), nomes como Alonso (2017) e Fuks, Borba e Ribeiro (2018) chegaram por vias diferentes a uma conclusão semelhante sobre este período: o principal rasgo do tecido social brasileiro no período pós-2013 foi a relação com as políticas petistas, polarizando a sociedade de tal forma que críticos à esquerda dos governos petistas foram enquadrados em um campo petista, e liberais não disruptivos foram enquadrados no que seria um campo fascista; houve um movimento narrativo de homogeneização dos campos políticos. ainda, de forma a complexificar e fechar este raciocínio mostrando como essa era uma brecha a ser explorada por agentes estrangeiros para aprofundar e instrumentalizar cismas dentro da sociedade brasileira, citamos Cepêda (2018, p. 68) ao constatar que

\footnotetext{
${ }_{9}$ Como exemplo, há o Google ensinando blogueiros que a melhor forma de obter lucro com os sites seria recebendo propagandas que pagavam por acesso no site, e o que mais movimentaria seus sites seria a publicação de propaganda antipetista, não importando ela ser real ou não. (GHEDIN; DIAS; RIBEIRO, 2020). ${ }^{10}$ Segundo o documento, juízes policiais federais compareceram ao evento. A conclusão da direção foi de que "a conferência foi um sucesso, [...] mobilizando um número significativo de profissionais brasileiros responsáveis por aplicar a lei em compartilhar experiências de combate ao crime[...]. O Projeto PONTES continuará a aproximar profissionais deste nicho estadunidenses e brasileiros de diversas maneiras, fortalecendo nossas relações e trocar conhecimentos” (WIKILEAKS, 2019, p. 5. Tradução dos autores).
} 
O projeto petista é visto como única força ordenadora da vida política brasileira no período. A adoção dessa postura é coerente com a proposição/posição ideológica do autor de aproximar o governo petista da chave do totalitarismo, do modelo cubano ou da "praga" do bolivarismo, percepção que faz parte do mito construído pela direita sobre o Estado-Partido do PT.

Aceitando que a crescente polarização política ocorre em momentos brevemente posteriores ou concomitantemente aos já citados treinamentos de lideranças ou suas atuações, os documentos comprovando atuação de uma inteligência sobre a política (inter)nacional a partir da manipulação social, a articulação em questão e seus efeitos são visíveis na realidade e, assim, não é possível descartar essas relações, a não ser que haja uma preferência pela interpretação via constelação de coincidências.

A partir do momento em que uma sociedade é polarizada em dois campos com sucesso, ela passa por um processo de condicionamento a estímulos externos, processo este que cria uma previsibilidade crescente sobre a forma como os atores dentro dos dois campos políticos vão atuar frente a determinados estímulos. O processo de divisão e manutenção desta por meio de estímulos é o que se chama de cismogênese: quando um ministro do Supremo Tribunal Federal, coincidentemente assistido por uma pequena série de oficiais generais do exército (SADI, 2020), solta uma nota dizendo-se chocado (MOURA, 2020) com o conteúdo de um vídeo vazado de reunião ministerial com o Presidente da República, ele cria estímulos na sociedade: o campo político de esquerda aposta todas suas fichas neste vazamento que finalmente criará força política para um possível impeachment, enquanto a direita mobiliza-se pela tese de que "estamos em uma Ditadura do STF” . O vídeo em si não tem maiores efeitos institucionais, reverberando mais na sociedade do que no interior do Estado: renova-se a coesão interna dentro dos e entre os campos, e reforça um princípio reativo na sociedade, com o qual a esquerda sempre reage à expectativa de um reavivamento das instituições, enquanto a direita reforça o culto à personalidade e sua narrativa antissistêmica. O produto da cismogênese torna-se dado interpretativo para o passo seguinte, não sendo um fato em si e tampouco devendo ser interpretado dessa forma, mas visto enquanto parte de um processo em constante desenvolvimento e adaptação à realidade:

como a cismogênese é um processo, ela precisa ocorrer sobre aspectos que já estavam colocados e pode atualizá-los intensificando-os, modificando-os, ou levando-os para uma outra condição. [...] ela pode acionar elementos que estavam em estado latente que começam a entrar em feedback[...] esses elementos não vão se resumir a um único evento, como por exemplo o impeachment de 2016; [...] eles começam antes e continuam depois [...] eles foram e são resultados de uma relação que se retroalimentou e ainda se retroalimenta (LEIRNER, 2020, p.179).

Essa dinâmica repete-se com grande frequência, permitindo a constatação de uma estrutura para essas ações que se baseia em uma disrupção vazia seguida por intensa mobilização dos campos políticos e nenhum efeito institucional: quando Bolsonaro disse ter provas de fraude nas eleições de 
2018 (ORTE, 2020); quando "ameaçou-se" apreender o celular do presidente para investigação (EXAME, 2020); quando um Ministro da Educação disse que retiraria o termo "ditadura militar" dos livros didáticos (JORNAL NACIONAL, 2019); quando criou-se enorme expectativa sobre o presidente cometer crime de responsabilidade pela possibilidade de ser vetor ativo do novo coronavírus durante a pandemia (CUNTO; MURAKAWA, 2020). Exemplos surgem cotidianamente, e ao bom observador cabe analisar as respostas da sociedade para fatos de tal espécie e perceber que as respostas dadas por ambos os lados se repetem com a mesma frequência das ditas polêmicas. Essa capacidade de moldar o debate e a forma como ele se dá, reforçando a normalidade constitucional no que cada dia mais revela-se um Estado falido com rompimento do pacto social para alimentar a confiança da esquerda nas instituições enquanto, ao mesmo tempo, alimenta a direita com suas pautas personalistas e autoritárias, criando então um cenário de caos social iminente que nunca se realiza, mas sempre ameaça, é o que se chama de caos administrado ou armamentização do caos.

\section{GUERRA IRREGULAR}

O conceito de guerra irregular é muito mais simples de explicar, tendo em vista seu papel dentro de uma guerra híbrida: se a revolução colorida é a tentativa de vencer a guerra antes de efetivamente entrar em um combate convencional, ou a cristalização da máxima de Sun-Tzu "a excelência suprema consiste em quebrares a resistência do inimigo sem lutar" (2011, p.55), a guerra irregular é o momento onde se abre mão dessa ideia e volta-se à violência aberta como modo de derrubar não só mais um governo, mas o Estado inteiro.

Quando a revolução colorida não basta para fazer a transição de regime, ela serve então ao propósito de dar corpo ao que virá a ser uma força irregular, uma guerrilha, e criar sua rede de apoio, com pessoas que forneçam abrigo, alimento, tratamento médico, recursos gerais, legitimidade política e moral, todos fatores necessários para a manutenção e possível sucesso do esforço de guerrilha (KORYBKO, 2018, p.92). Com essas condições, inicia-se uma guerra assimétrica entre a guerrilha e as forças armadas e policiais ligadas ao Estado, onde a ideia não é a vitória da guerrilha destruindo as forças estatais, mas sim convencendo parcelas cada vez maiores da sociedade de que o regime em vigência é ilegítimo e, a partir disso, crescer enquanto movimento, tanto aumentando suas fileiras com mais soldados quanto pressionando crescentemente o governo vigente; a guerrilha, como descrita por um de seus grandes intelectuais,

Levando em conta as possibilidades de desenvolvimento da guerra de guerrilha, que é transformada com o crescimento da potência operacional do bando guerrilheiro até chegar em uma guerra de posições, esse tipo de guerra [...] deve ser considerado 
como um embrião, um prelúdio do outro (GUEVARA, 1969, p.6. Tradução dos autores) $)^{11}$.

Esclarecido o caráter da guerrilha, o leitor pode estar se perguntando: "se a guerra irregular faz parte da guerra híbrida e esse fenômeno veio a se manifestar no Brasil, como não tivemos uma guerra irregular no Brasil?”; propomos darmos os nós entre teoria e realidade: uma guerra híbrida é aplicada necessariamente pelos Estados Unidos, país que desenvolveu essa técnica, para interferir na política interna de países que possam interferir em seus interesses estratégicos. Korybko faz a leitura dos países eurasiáticos, onde distância e influência de potências regionais fazem necessária a criação ou fortalecimento de atores fora do aparelho de Estado para fazer sua política por procuração. Por outro lado, na América Latina, desde os processos iniciais de industrialização no início do Século XX, passando pelo início do pós-Segunda Guerra até o início da Operação Condor, houve uma aproximação intensa entre as Forças Armadas de países da região e as Forças Armadas estadunidenses. A leitura que não é feita por Korybko (2018) é a de que não há necessidade, por parte do imperialismo, de chegar ao ponto de fomentar uma guerra irregular quando as próprias forças regulares podem ser o agente representante dos interesses estadunidenses em seus países; a tomada do Estado na América Latina vem em duas frentes, com as revoluções coloridas exógenas ao Estado e as Forças Armadas administrando a rearticulação endógena das instituições, não havendo, até então, a necessidade pela criação de uma guerra de guerrilha.

Como casos que endossam esse raciocínio, podemos olhar, além do Brasil, os casos boliviano e paraguaio, que expõem pequenas mutações em uma mesma estrutura de modus operandi, onde os Estados Unidos fazem uso da abordagem indireta. Na Bolívia, a irrupção de um levante paramilitar reacionário contra o presidente Evo Morales, após sua reeleição, foi o evento para transição do regime: o Exército e as forças policiais, em vez de cumprirem com seus respectivos papéis legais, tentam primeiramente prender o presidente eleito e, ao verem que ele escapou de seu cerco, "aconselham-no" a deixar o cargo para a volta da famosa normalidade democrática ${ }^{12}$, apoiando então Jeanine Áñez, uma reescrita da tática Guaidó com auxílio estadunidense (VALENCIA, 2019), auxílio esse nos exatos moldes do que configura uma revolução colorida; no Paraguai, o golpe de 2012 que removeu Fernando Lugo da presidência teve outras características dentro da mesma estrutura já exposta: como um relâmpago, a oposição -e parte do que anteriormente compunham sua basevotaram em bloco pelo início de um processo de impeachment no dia 20 de junho e efetivaram o dito impeachment no dia 22 do mesmo mês, ignorando qualquer direito que o processado pudesse ter

\footnotetext{
${ }_{11}$ "Taking account of the possibilities of development of guerrilla warfare, which is transformed with the increase in the operating potential of the guerrilla band into a war of positions, this type of warfare [...] is to be considered as an embryo, a prelude, of the other."

12 "Depois de analisar a situação conflituosa interna, sugerimos que o presidente do Estado renuncie a seu mandato presidencial, permitindo a pacificação e a manutenção da estabilidade pelo bem de nossa Bolívia." Williams Kaliman, então Chefe do Exército Boliviano (apud MOLINA, 2020).
} 
com aval da Suprema Corte do país, que negou seu direito à defesa (MONTEIRO, 2018, p.76-79). Coincidentemente,

O treinamento das forças de segurança paraguaias estavam entre os principais programas financiados pela USAID [sic]. Entre 2005 e 2010, cerca de mil militares e policiais foram treinados - a maioria em 2009, ano seguinte à posse de Lugo - e dali saíram alguns comandantes das Forças Armadas nomeados por Franco quando assumiu o poder. (VIANA, 2013).

A nota mais importante que fica ao terminar este raciocínio é de que o papel das Forças Armadas é preponderante sobre quaisquer rumos que um regime tome; independentemente de um golpe armado ou um neogolpe (MONTEIRO, 2018), onde as instituições aparentam normalidade enquanto agem de forma ilegal, na conjuntura sociopolítica atual, nenhum lado dará um golpe contrariando o veredito dessa instituição ou, ainda, mais dificilmente fará oposição aberta contra ela. Enquanto no Brasil há uma trirrelação entre Forças Armadas e Judiciário (relação que pode ser vista como oposição ou conluio a depender da fonte: generais "auxiliando" os presidentes do STF, ou o Chefe de Exército ameaçando o Estado de Direito caso fosse feita uma decisão contrária ao seu querer) ${ }^{13}$ para controlar os rumos do Poder Executivo com preponderância da primeira, uma clara participação sua no governo e tentativa de aparelhamento da burocracia do Estado (SANTOS, 2019); na Bolívia, os militares não foram os agentes centrais no processo do golpe, mas foram os fiadores do mesmo ao "convidarem" o Presidente eleito a se retirar em vez de fazer cumprir a ordem democrática e aceitarem, além disso, o emprego violento para conter a revolta popular decorrente do golpismo:

Como disse à época José Miguel Vivanco, diretor da Human Rights Watch for America, as medidas adotadas pelo governo 'parecem priorizar a brutalidade para neutralizar opositores e críticos e dar às Forças Armadas um cheque em branco para cometer abusos, em vez de trabalhar para restaurar o Estado de Direito no país. (ANGEE, 2019. Tradução dos autores) ${ }^{14}$.

No Paraguai, o mesmo ocorreu, com a benção dos militares para o golpe brando, incluindo sua ascensão dentro dos mecanismos de sustentação do novo governo, como demonstrado anteriormente. Com isso, chega-se ao cerne do papel militar dentro da nova configuração política latino-americana: independentemente de sua potência política, para além de bélica, que pode ou não

\footnotetext{
${ }^{13}$ A criação de uma agenda autoritária que busca institucionalizar ações arbitrárias contra inimigos genéricos em uma política "antiterror" pautada pelo ex-Major de Infantaria Vitor Hugo de Araujo Almeida no PL1595/2019 é o símbolo perfeito. Conforme apresenta, "Esta Lei será aplicada também para prevenir e reprimir a execução de ato que, embora não tipificado como crime de terrorismo [...] aparente ter a intenção de intimidar ou coagir a população civil ou de afetar a definição de políticas públicas por meio de intimidação, coerção, destruição em massa[...].” (p.2).

14 "Según dijo en su momento José Miguel Vivanco, director de Human Rights Watch para América, las medidas adoptadas por el gobierno 'parecen priorizar la brutalidad para neutralizar a los oponentes $y$ críticos y otorgan a las fuerzas armadas un cheque en blanco para cometer abusos, en vez de trabajar para restablecer el estado de derecho en el país."
} 
permitir o domínio da sociedade civil e política, as Forças Armadas agem por meio da abordagem indireta, estando sempre em meio aos projetos como um supervisor, diferentemente dos anos 1950 e 1960 onde assumiram os papéis políticos centrais com a instituição na frente, assumindo também todo o desgaste sociopolítico decorrente da impopularidade causada por suas ações autoritárias.

Mas não nos enganemos: se as instituições do Estado de Direito funcionam apenas quando é permitido que elas funcionem, quando penetram dentro do aparato burocrático e tomam o controle da política de Estado, controlando a possibilidade de atuação de governos eleitos, não houve então um golpe? A natureza de um golpe é estética, e não pragmática, então, sem tanques e fuzis não há possibilidade de quebra do pacto político que firmou um Estado? Uma ação é em si menos autoritária porque foi escrita na legislação vigente? É possível falar em normalidade legal a partir do momento em que houve uma reorganização absolutamente dependente da ruptura com a ordem previamente estabelecida?

\section{CONSIDERAÇÕES FINAIS}

Este artigo tem três propósitos: primeiramente, explicar resumidamente a leitura proposta por Korybko enquanto mostra empiricamente sua aplicação calcada em fatos de escalas variadas, desde a motivação geopolítica imperialista por trás da criação e aplicação dessa técnica até a micropolítica nacional, falando da forma como atores políticos são organizados para efetivamente materializar esse projeto, mostrando que essa teoria não deve ser interpretada levianamente: nada do que o autor levanta como meio de aplicação da guerra híbrida é minimamente fantasioso, seja pelo lado técnico que a tecnologia possibilitou para interpretar uma sociedade por finalidade e de forma puramente utilitária, seja pelo funcionamento focado em instituições informais; é difícil crer que se negue a possibilidade de um conchavo entre elites nacionais e o imperialismo para beneficiar o mesmo, um fato social que, até o último governo democrático liberal que tivemos, estava a apenas 30 anos de distância. Feita essa colocação, deve-se ter também humildade para não ver-se acima do mundo como o observador absolutamente objetivo que um viés positivista poderia criar. O diálogo entre diferentes interpretações da realidade é de fundamental importância para o processo de criação complexificada de conhecimento da qual depende a ciência; se propomos uma interpretação da realidade por meio desta técnica, não descartamos as demais como inferiores apenas pela discordância, mas buscamos entendê-la de forma crítica e através do debate criar interpretações cada vez mais refinadas a partir de nossa posição.

Um segundo propósito é defender que o conceito de guerra híbrida é menos focado em ser uma criação teórica pautada em explicar um fato social, mas sim explicar o funcionamento de uma técnica que em si cria fatos sociais; ele não deve ser interpretado como um conceito estruturante de uma teoria global tal qual a mercadoria no marxismo ou a agência para Weber, poliarquia para Dahl 
ou o bricolage de Lévi-Strauss, mas sim como parte de uma explicação conjuntural da realidade, tal qual o intervencionismo militar direto sobre o qual se debruçaram estudiosos durante boa parte do século XX; dizer que guerras híbridas são, enquanto conceito, de esquerda ou direita, seria o equivalente a dizer que, se Marx descreve o capital, é por ele claramente ser capitalista. Um autor não necessariamente concorda ou discorda do conceito em si, mas julga-o objetivamente adequado para fazer um retrato da realidade. O texto escrito por Korybko (2018) deve ser entendido em uma chave parecida a O Príncipe, de Maquiavel: enquanto o autor clássico faz a descrição de uma técnica no estilo de um manual a ser seguido por determinados atores, o autor contemporâneo aglutina e analisa os diversos manuais que instruem tecnicamente diversos atores sociais a se movimentarem politicamente, estudando a macrorrelação entre estes, a motivação de sua criação e aplicação e suas consequências.

Isso dito, entende-se, claro, que as guerras híbridas enquanto fenômeno sociopolítico não são mais do que efeito geopolítico da acentuação das crises do capital internacional, realinhando as relações centro-periferia e oriente-ocidente para maximizar a extração de riquezas e bancar uma corrida tecnológica entre as novas potências hemisféricas ao custo de um projeto de subdesenvolvimento e finalidade agroexportadora de toda economia periférica, o que nos leva ao terceiro propósito: ao falarmos do projeto designado para os citados fins, com tamanha qualidade técnica, fruto de um longo processo histórico de desenvolvimento, muitos leitores tendem a creditar um fatalismo insuperável ao texto e autor, descrevendo-o como um pessimista e seu conceito como algo entre o melancólico e o derrotista. Quanto a isso, podemos apenas dizer que é a função social do labor do cientista social descrever a realidade da forma mais fidedigna o possível aos seus achados; se esta é a situação, descrevê-la com eufemismos é um desserviço e nada além disso.

O que pode se aprender estudando este texto é que há um ordenamento em fatos normalmente tidos como randômicos, e entendendo seus pressupostos, é possível interpretar as situações presentes a partir de um entendimento do método utilizado para construí-las e entender a correlação entre tais fatos, assim como criar diferentes cenários do que uma situação pode estar querendo criar: isso não possibilita prever o futuro, mas possibilita entender determinados padrões que repetem-se e, portanto, podem ser compreendidos como ferramentas para determinados fins. Aos que buscam mudança, uma leitura mais atenta do texto e uma mente criativa deixam brechas.

*Artigo recebido em 15 de agosto de 2020, aprovado em 15 de janeiro de 2021. 


\section{REFERÊNCIAS}

ALMEIDA, Vitor Hugo de Araujo. PL1595/2019. Brasília, 2019.

ALONSO, Ângela. A Política das Ruas: Protestos em São Paulo de Dilma a Temer. In: Novos Estudos CEBRAP, Edição Especial, p.49-58, 2017.

ANGEE, Gremaud. Gobierno interino de Bolivia revoca polémico decreto para militares. In: CNN Español. 2019. <https://cnnespanol.cnn.com/2019/11/28/alerta-bolivia-presidentainteriana-revoca-controversial-decreto-4078/>. Acesso em: 31 jan. 2021.

CALWALLADR, Carole. 'I made Steve Bannon's psychological warfare tool': meet the datawar whistleblower. In: The Guardian. 2020. <https://www.theguardian.com/news/2 018/mar/17/data-war-whistleblower-christopher-wylie-faceook-nix-bannon-trump >. Acesso em: 31 jan. 2021.

CEPÊDA, Vera Alves. A Nova Direita no Brasil: Contexto e Matrizes Conceituais. In: Revista Mediações, v.23, $\mathrm{n}^{\mathrm{O}}$ 2, p.75-122, Londrina, 2018.

CIO. Mercado para Cientista de Dados é um dos Mais Promissores em TI. 2020. $<$ https://cio.com.br/mercado-para-cientistas-de-dados-e-um-dos-mais-promissores-em-ti/>.

Acesso em: 31 jan. 2021.

CUNTO, Raphael Di; MURAKAWA, Fabio. Planalto teme desfecho sobre exame médico. In: Valor. 2020. <https://valor.globo.com/politica/noticia/2020/05/12/planaltoteme-desfecho-sobre-exame-medico.ghtml>. Acesso em: 31 jan. 2021.

DATA SCIENCE ACADEMY. Por Que Cientistas de Dados Continuam em Alta Demanda? 2020. <http://datascienceacademy.com.br/blog/por-que-cientistas-de-dados-continuam-emalta-demanda/>. Acesso em: 31 jan. 2021.

DEPARTMENT OF DEFENSE. JP 1-o2 Department of Defense Dictionary of Military and Associated Terms. Government Printing Office, Estados Unidos Da América, 2007.

EXAME. STF envia à PGR pedido da oposição para apreender celular de Bolsonaro. 2020. <https://exame.com/brasil/stf-envia-a-pgr-pedido-da-oposicao-para-apreender-celular-debolsonaro/>. Acesso em: 31 jan. 2021.

EXAME. Cientista de Dados: a Profissão do Futuro Continua em Alta. 2019. <https://exame.com/carreira/cientista-de-dados-a-profissao-do-futuro-continua-em-alta/>. Acesso em: 31 jan. 2021.

FUKS, Mario; BORBA, Julian; RIBEIRO; Ednaldo. Polarização, Antipartidarismo e Tolerância Política no Brasil. In: Anais do 42 Encontro da Anpocs, Caxambu, 2018.

FUKUYAMA, Francis. O Fim da História e o Último Homem. Editora Rocco, Rio de Janeiro, 1992.

GASPAR, Ricardo Carlos. A Trajetória da Economia Mundial. In: Cadernos Metrópole, v.17, $\mathrm{n}^{0} 33$, p.265-296, São Paulo, 2015.

GAGLIONI, Cesar. O que há sobre o Brasil nos documentos da Cambridge Analytica. In: Nexo Jornal. 2020. <https://www.nexojornal.com.br/expresso/2020/o1/o6/O-que-h\%C3\%A1sobre-o-Brasil-nos-documentos-da-Cambridge-Analytica>. Acesso em: 31 jan. 2021. 
GHEDIN, Rodrigo; DIAS, Tatiana; RIBEIRO, Paulo Victor. Grana por Cliques. In: Intercept. 2020. <https://theintercept.com/2019/11/19/fake-news-google-blogueiros-

antipetistas/?fbclid=IwAR2t533l_uCx7rhpJT93TwFjpmz-

FNYkAJMOKxoog_ISNWLayo3s8FOVR6M >. Acesso em: 31 jan. 2021.

GUEVARA, Ernesto. Guerrilla Warfare. Vintage Books, Estados Unidos, 1969.

JORNAL NACIONAL. Ministro Vélez diz que vai revisar livros didáticos sobre golpe de 64 e ditadura. In: G1. 2019. <https://g1.globo.com/jornalnacional/noticia/2019/04/o4/ministro-velez-diz-que-vai-revisar-livros-didaticos-sobre-golpe-de64-e-ditadura.ghtml>. Acesso em: 31 jan. 2021.

KENETT, Ron S.; REDMAN, Thomas C. The Real Work of Data Science: Turning Data into Information, Better Decisions, and Stronger Organizations, Editora Wiley, Inglaterra, 2019.

KORYBKO, Andrew. Guerras Híbridas: das Revoluções Coloridas aos Golpes. Editora Expressão Popular, São Paulo, 2018.

LEAL, Paulo Cesar. A Guerra Híbrida: Reflexos para o Sistema de Defesa no Brasil. In: Doutrina Militar Terrestre em Revista, vol.4, n.9, pp. 6-17, Brasília, 2016.

LEIRNER, Piero de Camargo. Irregular Anthropology: Researching for the Military. In: CARREIRA, Helena; CASTRO, Celso; FREDERIC, Sabina (Org.). Researching the Military, p.78-91. Routledge, Londres, 2016.

LEIRNER, Piero de Camargo. O Brasil no Espectro de uma Guerra Híbrida: Militares, Operações Psicológicas e Política em uma Perspectiva Etnográfica. Alameda Editorial, São Paulo, 2020.

LOEB, Eric; MOORE, Steven E. Make Data Science Accessible for the Pentagon. In: War on the Rocks. 2020. <https://warontherocks.com/2020/02/make-data-science-accessible-for-thepentagon/>. Acesso em: 31 jan. 2021.

MENDONÇA, Antônio. A Caminho de uma Recaída da Economia Mundial? Ainda Algumas Notas Sobre a Natureza da Crise Económica e Financeira de 2008 - 2009 e os Seus Impactos na Economia Europeia. In: Revista Lusíadas: Economia e Empresa, nº 26, Portugal, 2019.

MINISTÉRIO DA DEFESA. MD35-G-o1 Glossário das Forças Armadas. Brasília, 2007.

MONTEIRO, Leonardo Valente. Os Neogolpes e as Interrupções de Mandatos Presidenciais na América Latina: os Casos de Honduras, Paraguai e Brasil. In: Revista de Ciências Sociais, p.5597, v.49, $\mathrm{n}^{\mathrm{0}} 1$, Fortaleza, 2018.

MOLINA, Fernando. Evo Morales renuncia na Bolívia após militares cobrarem sua saída. In: El País. 2020. <https://brasil.elpais.com/brasil/2019/11/10/internacional/1573419 777_926417.html>. Acesso em: 31 jan. 2021.

MOSKOS, Charles C.; WILLIAMS, John Allen; Segal, David R. Armed Forces After the Cold War. In: The Postmodern Military: Armed Forces After the Cold War, p.1-13, The Oxford University Press, Estados Unidos da América, 2000.

MOURA, Rafael Moraes. Celso de Mello ficou incrédulo com vídeo de reunião e tendência é divulgar íntegra. In: Estadão. 2020. <https://politica.estadao.com.br/blogs/faustomacedo/celso-de-mello-ficou-incredulo-com-video-de-reuniao-e-tendencia-e-divulgar-integravideo/>. Acesso em: 31 jan. 2021. 
ORTE, Paola de. Pela $\mathbf{1}^{\mathbf{a}}$ vez, Bolsonaro diz ter provas de fraude nas eleições de 2018, mas não as apresenta. In: Revista Valor. 2020. <https://valor.globo.com/politi ca/noticia/2020/o3/o9/pela-1-vez-bolsonaro-diz-ter-provas-de-fraude-nas-eleies-de-2018-masno-as-apresenta.ghtml>. Acesso em: 31 jan. 2021.

OUR WORLD IN DATA. Gráfico Progressivo de Pib per Capita Mundial de 1990 a 2017. <https://ourworldindata.org/grapher/gdp-per-capitaworldbank?tab=chart\&country= OWID_WRL\&region=World $>$. Acesso em: 31 jan. 2021.

SADI, Andrea. General Ajax Porto Pinheiro assumirá assessoria de Toffoli no Supremo. In: G1. 2020. <https://g1.globo.com/politica/blog/andreia-sadi/post/2018/11/27/general-ajaxporto-pinheiro-assumira-assessoria-de-toffoli-no-stf.ghtml>. Acesso em: 31 jan. 2021.

SANTOS, Rafa. Villas Bôas volta a intimidar STF antes de sessão sobre $2^{a}$ instância. In: Conjur. 2019. <https://www.conjur.com.br/2019-out-16/general-escreve-mensagemintimidatoria-antes-julgamento >. Acesso em: 31 jan. 2021.

SMITH, Marcie. Getting Gene Sharp Wrong. In: Jacobin Magazine. 2020. <https://www.jacobinmag.com/2019/12/gene-sharp-george-lakey-neoliberal-nonviolence>. Acesso em: 31 jan. 2021.

SUN-TZU. A Arte da Guerra. Hunterbooks Editora, São Paulo, 2011.

TELLES, Helcimara. A Direita Vai às Ruas: o antipetismo, a corrupção e democracia nos protestos antigoverno. In: Revista Ponto e Vírgula, nº19, p.97-125, São Paulo, 2016.

VALENCIA, Adrián Sotelo. Bolivia: del Progresismo al Golpe de Estado y la Réplica de Guaidó. In: Marx e o Marxismo - Revista NIEP, p.430-434, v.7, $\mathrm{n}^{0} .13,2019$.

VALENTE, Jonas. Brasil tem 134 milhões de usuários de internet, aponta pesquisa. In: Agência Brasil. 2020. <https://agenciabrasil.ebc.com.br/geral/noticia/2020-05/brasil-tem-134milhoes-de-usuarios-de-internet-aponta-pesquisa>. Acesso em: 31 jan. 2021.

VIANA, Natalia. Paraguai: os EUA e o Impeachment. In: A Pública. 2013. <https://apublica.org/2013/o2/paraguai-os-eua-impeachment/>. Acesso em: 31 jan. 2021.

VICARIO, Grazia; COLEMAN, Shirley. A Review of Data Science in Business and Industry and a Future View. In: Applied Stochastic Models in Business and Industry, vol.36, $\mathrm{n}^{\mathrm{o}}{ }_{1}, \mathrm{p} .6-18$, Estados Unidos da América, 2020.

WIKILEAKS. Brazil: Illicit Finance Conference Uses The "T" Word, Successfully. 2019. <https://wikileaks.org/plusd/cables/o9BRASILIA1282_a.html>. Acesso em: 31 jan. 2021. 